\title{
Bacterial $N$-acylhomoserine lactone-induced apoptosis in breast carcinoma cells correlated with downmodulation of STAT3
}

\author{
Li Li, Doreen Hooi, Siri Ram Chhabra, David Pritchard and Peter E Shaw
}

Oncogene (2004) 23, 9450. doi:10.1038/sj.onc.1208361

Correction to: Oncogene (2004) 23, 4894-4902. doi:10.1038/sj.onc.1207612

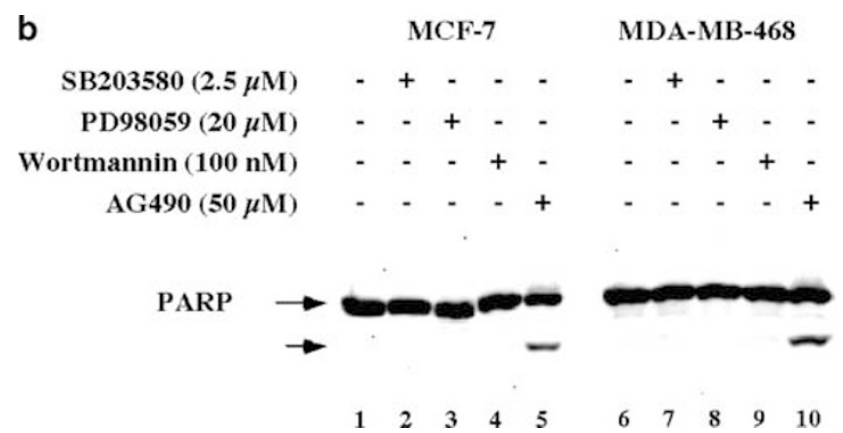

Figure 6b

\section{Mitochondrial proapoptotic ARTS protein is lost in the majority of acute lymphoblastic leukemia patients}

Ronit Elhasid, Dvora Sahar, Ayellet Merling, Yifat Zivony, Asaf Rotem, Miriam Ben-Arush, Shai Izraeli, Dani Bercovich and Sarit Larisch

Oncogene (2004) 23, 9450. doi:10.1038/sj.onc. 1208363

Correction to: Oncogene (2004) 23, 5468-5475. doi:10.1038/sj.onc. 1207725

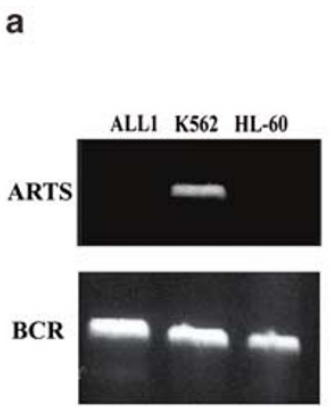

b
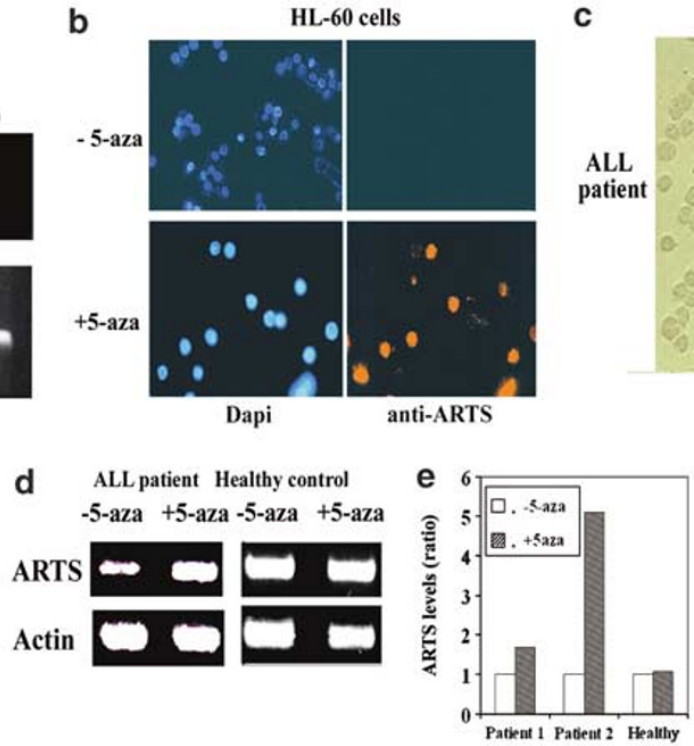

Due to a typesetting error, Figure 6 appeared in monotone rather than colour. The correct version of the figure is given below. c

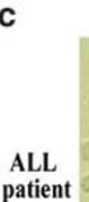

-5 -aza
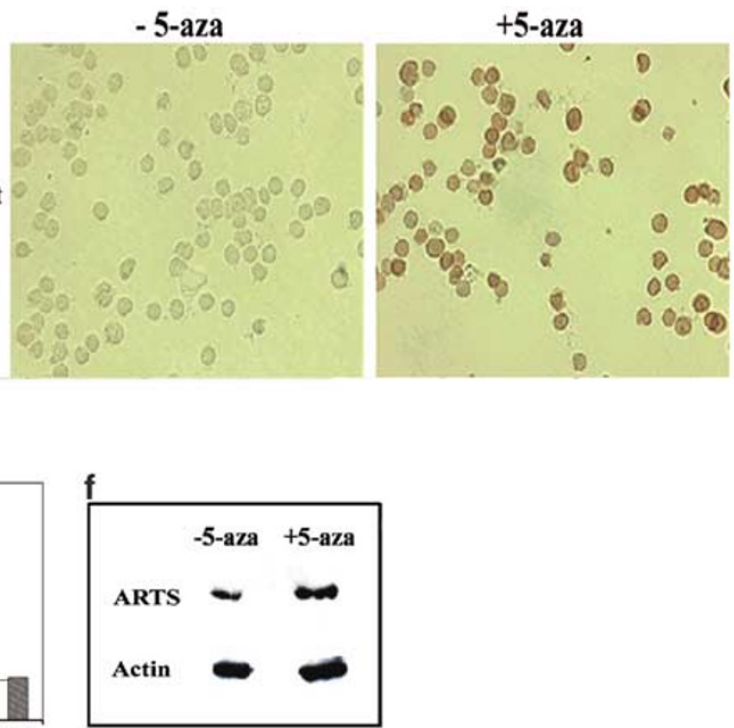